This article is licensed under the Creative Commons Attribution-NonCommercial 4.0 International License (CC BY-NC) (http://www.karger.com/Services/OpenAccessLicense). Usage and distribution for commercial purposes requires written permission.

\title{
Recognition of Extraperitoneal Colonic Perforation following Colonoscopy: A Review of the Literature
}

\author{
Abhinav Tiwari Himani Sharma Khola Qamar Thomas Sodeman \\ Ali Nawras \\ University of Toledo Medical Center, Toledo, OH, USA
}

\section{Keywords}

Extraperitoneal colonic perforation - Colonoscopy · Ulcerative colitis · Literature review ·

Symptoms

\begin{abstract}
Colon perforation is an uncommon but serious complication of colonoscopy. It may occur as either intraperitoneal or extraperitoneal perforation or in combination. The majority of colonic perforations are intraperitoneal, causing air and intracolonic contents to leak into the peritoneal space. Rarely, colonic perforation can be extraperitoneal, leading to the passage of air into the retroperitoneal space causing pneumoretroperitoneum, pneumomediastinum, pneumopericardium, pneumothorax, and subcutaneous emphysema. A literature review revealed that 31 cases of extraperitoneal perforation exist, out of which 20 cases also reported concomitant intraperitoneal perforation. We report the case of a young female with a history of ulcerative colitis who developed combined intraperitoneal and extraperitoneal perforation after colonoscopy. We also report the duration of onset of symptoms, clinical features, imag-
\end{abstract}


ing findings, site of leak, and treatment administered in previously reported cases of extraperitoneal colonic perforation.

\section{Introduction}

Colonoscopy is a commonly performed procedure for the diagnosis and treatment of a wide range of conditions and symptoms and for the screening and surveillance of colorectal neoplasia. Colonic perforation occurs in $0.03-0.8 \%$ of colonoscopies $[1,2]$ and is the most feared complication with a mortality rate as high as $25 \%$ [1]. It may result from mechanical forces against the bowel wall, barotrauma, or as a direct result of therapeutic procedures. Colon perforation may occur as either intraperitoneal or extraperitoneal perforation or in combination. The majority of colonic perforations are intraperitoneal, causing air and intracolonic contents to leak into the peritoneal space. This manifests as persistent abdominal pain and abdominal distention, later progressing to peritonitis. A plain radiograph may demonstrate free air under the diaphragm.

Rarely, colonic perforation can be extraperitoneal, leading to the passage of air into the retroperitoneal space, which then diffuses along the fascial planes and large vessels causing pneumoretroperitoneum, pneumomediastinum, pneumopericardium, pneumothorax, and subcutaneous emphysema. Such patients can have atypical presentation, including subcutaneous crepitus, neck swelling, chest pain, and shortness of breath after colonoscopy. The combination of intraperitoneal and extraperitoneal perforation has also been reported. A literature review revealed that 31 cases of extraperitoneal perforation exist, out of which 20 cases also reported concomitant intraperitoneal perforation. We report the case of a young female with a history of ulcerative colitis (UC) who developed combined intraperitoneal and extraperitoneal perforation after colonoscopy. We also report the duration of onset of symptoms, clinical features, imaging findings, site of leak, and treatment administered in previously reported cases of extraperitoneal colonic perforation.

\section{Case Presentation}

A 41-year-old Caucasian female with a history of UC on vedolizumab presented with complaints of 7-10 daily episodes of watery diarrhea for 2 days associated with crampy, intermittent lower abdominal pain and subjective fever without any chills. She denied any recent hospitalization, antibiotic exposure, travel, or sick contact. She appeared cachectic with a body mass index of 18.7 and reported a 15-pound weight loss over the last 2 months. On examination, she had a temperature of $100.4^{\circ} \mathrm{F}$, a blood pressure of $110 / 78 \mathrm{~mm} \mathrm{Hg}$, and a heart rate of $105 / \mathrm{min}$, and abdominal exam revealed hyperactive bowel sounds, diffuse tenderness without guarding, rigidity, or rebound tenderness. Notable lab abnormalities included erythrocyte sedimentation rate of $43 \mathrm{~mm} / \mathrm{h}$, white blood cell count of $12.6 \times 10^{9} / \mathrm{L}$, hemoglobin of $10.8 \mathrm{~g} / \mathrm{dL}$, and albumin of $2.6 \mathrm{~g} / \mathrm{dL}$. Stool Clostridium difficile PCR and ova/parasites screen were negative. Computerized tomography (CT) scan of the abdomen demonstrated diffuse colitis with a transverse colon diameter of $2.4 \mathrm{~cm}$ and right-sided py- 


\section{Case Reports in \\ Gastroenterology}

Case Rep Gastroenterol 2017;11:256-264

(c) 2017 The Author(s). Published by S. Karger AG, Basel www.karger.com/crg

Tiwari et al.: Recognition of Extraperitoneal Colonic Perforation following Colonoscopy: A Review of the Literature

elonephritis. Given her clinical features and evidence of colitis on imaging, she was thought to be having an exacerbation of UC and was started on intravenous (IV) normal saline, IV methylprednisolone, and IV ciprofloxacin/metronidazole for pyelonephritis. She reported considerable improvement in her symptoms, with the resolution of diarrhea and abdominal pain over the next few days. Her quality of life was poor due to multiple exacerbations of UC from medication noncompliance; therefore, surgical intervention was planned. Colonoscopy was performed on day 7 of hospitalization. The colonoscope was passed through the anus under direct visualization and was advanced with ease to the transverse colon. The scope was withdrawn, and the mucosa was carefully examined, which revealed mild colitis in the distal transverse colon, while the descending colon and the sigmoid colon showed severe colonic inflammation. The mucosa appeared cobblestoned, edematous, erythematous, and ulcerated. Biopsies were obtained from the sigmoid colon and descending colon. The quality of the preparation was good, and the patient tolerated the procedure well. Histology was consistent with UC.

The following day, she was noted to have subcutaneous emphysema of the chest wall. CT of the chest, abdomen, and pelvis revealed large pneumoperitoneum, pneumomediastinum, and pneumopericardium with air tracking all the way up into the neck (Fig. 1, Fig. 2). The patient remained asymptomatic. She had an exploratory laparotomy, was found to have transverse colon perforation, and underwent subtotal colectomy with end ileostomy. The patient had an uncomplicated postoperative course and was discharged home in stable condition.

\section{Discussion}

The perforation rate in diagnostic colonoscopy ranges from 0.03 to $0.8 \%$, and in therapeutic colonoscopy it ranges from 0.15 to $3 \%[1,2]$. In the majority of cases, the perforation after a colonoscopy is intraperitoneal, and only a few cases reporting extraperitoneal perforation exist in the literature (Table 1).

\section{Mechanism of Extraperitoneal Air Leak}

In extraperitoneal perforation, extraluminal air may reach the different body compartments in neck and chest. Maunder et al. [3] described the route of extraperitoneal gas. The soft-tissue compartment of the neck, thorax, and abdomen contains 4 regions: (1) the subcutaneous tissue, (2) prevertebral tissue, (3) visceral space, and (4) previsceral space. These spaces are connected along the neck, chest, and abdomen. Air leaked into one of these spaces may pass into others along fascial planes and large vessels, eventually reaching the neck and pericardial, mediastinal, and pleural space.

\section{Procedure Characteristics}

Iatrogenic colonoscopic perforations can result from diagnostic and therapeutic procedures. Diagnostic perforation is the result of mechanical disruption of the colonic wall induced directly by the tip of the endoscope or by considerable stretching of the bowel, especially when loops are formed or the endoscope is advanced by the slide-by technique. Therapeutic perforations can be induced by any intervention involving dilation or electrocoagula- 


\section{Case Reports in \\ Gastroenterology}

Case Rep Gastroenterol 2017;11:256-264

(c) 2017 The Author(s). Published by S. Karger AG, Basel www.karger.com/crg

Tiwari et al.: Recognition of Extraperitoneal Colonic Perforation following Colonoscopy: A Review of the Literature

tion, including treatment of arteriovenous malformations and, most commonly, polypectomy $[4,5]$. Out of 32 cases of extraperitoneal perforation (Table 1), 19 perforations (59\%) occurred after diagnostic colonoscopy, and biopsies were obtained in 7 of them. Thirteen perforations (40\%) were the result of colonoscopy involving some form of intervention, including polypectomy (Table 2).

\section{Onset of Symptoms}

Perforations can be detected immediately during the procedure by visualizing the perforation site, or the patient may become symptomatic after a few hours to days. On reviewing 32 cases of extraperitoneal perforations (Table 1), we found out that in 16 cases (52\%), the perforation was detected within $1 \mathrm{~h}$, in 9 cases (29\%) within 1-24 h, and in 6 cases (19\%) $>24 \mathrm{~h}$ after the procedure. Development of subcutaneous emphysema presents with neck or facial swelling (which is readily visible); this may be the reason for earlier detection of extraperitoneal perforations (Table 2).

\section{Symptoms of Extraperitoneal Perforation}

After a regular colonoscopy, many patients experience some crampy abdominal pain because of retained air in the bowel. Intraperitoneal perforation can cause peritoneal irritation with rebound tenderness, rigidity of the abdomen, accompanied by fever, leukocytosis, and tachycardia. The most common presenting clinical feature of extraperitoneal colonic perforation was subcutaneous emphysema of the neck, face, or upper chest seen in 21 patients (65\%), followed by abdominal pain seen in 11 patients (34\%) and dyspnea in 8 patients $(25 \%)$. Close to $10 \%$ of patients remained asymptomatic (Table 2). In cases of isolated extraperitoneal perforation, only 1 patient (8\%) presented with abdominal pain.

\section{Imaging}

Of the 32 cases presented in Table 1, 29 patients (90\%) had pneumomediastinum, 13 patients (40\%) had pneumothorax, and 5 patients $(15 \%)$ had pneumopericardium on chest X-ray or CT scan. Plain radiographs are usually diagnostic of perforations, but CT scan is recommended if findings are not definitive or if the presence of free air cannot be ruled out by radiographs alone.

\section{Site of Perforation}

The most common site of extraperitoneal perforation was rectosigmoid in 18 patients (56\%) followed by the cecum in 3 cases (9\%). Panteris et al. [6] also reported that the most frequent site of all types of perforation is the sigmoid followed by the cecum. The sigmoid colon is the most common site of perforation (1) as shearing forces applied during endoscope insertion cause trauma to the sigmoid colon and (2) as it is a common location of diverticula and polyps, both of which make mechanical or thermal injury more likely in this region. The cecum is well known to have a thinner muscular layer and a larger diameter than the rest of the bowel, both of which render it susceptible to barotraumas. Our patient had UC with friable colonic mucosa which predisposes to perforation. 


\section{Treatment and Prognosis}

The decision whether surgery or nonoperative treatment should be employed will depend on the type of injury, the quality of bowel preparation, the underlying colonic pathology, and the clinical stability of the patient $[7,8]$. A selected number of patients can be treated conservatively with bowel rest, IV antibiotics, and close observation [9-11]. Surgical options include primary repair of the perforated bowel segment or segmental resection [12]. Surgical intervention is more likely to be successful if the perforation is diagnosed earlier than 24 $\mathrm{h}$ after perforation; hence, early recognition and treatment are imperative $[13,14]$. In cases of extraperitoneal perforation, 17 patients $(53 \%)$ were treated conservatively, while 15 patients $(47 \%)$ needed operative management. Twelve patients $(60 \%)$ with combined intraperitoneal and extraperitoneal perforation needed surgical intervention (Table 2), while only 3 patients $(25 \%)$ with isolated extraperitoneal perforation needed surgery. All patients recovered well with no reported mortality.

In summary, we described a case of combined intraperitoneal and extraperitoneal perforation after diagnostic colonoscopy in a patient with UC. A literature review of cases reporting extraperitoneal perforation revealed that the majority of such perforations were detected immediately after the procedure. Most patients presented with subcutaneous emphysema of the neck, face, or upper chest followed by abdominal pain. On imaging, pneumomediastinum was the most common finding, and the most common site of extraperitoneal perforation was the rectosigmoid area. Conservative treatment was successful in the majority of cases.

Therefore, physicians should be cognizant of the possibility of extraperitoneal perforation whenever a patient presents with subcutaneous emphysema, chest pain, and/or shortness of breath after colonoscopy. Abdominal pain is not seen in a majority of patients; therefore, an absence of abdominal pain and abdominal tenderness should not be a reason to exclude colonic perforation.

\section{Statement of Ethics}

The authors have no ethical conflicts to disclose.

\section{Disclosure Statement}

The authors declare that they have no conflict of interest.

\section{References}

1 Luning TH, Keemers-Gels ME, Barendregt WB, et al: Colonoscopic perforations: a review of 30,366 patients. Surg Endosc 2007;21:994-997.

-2 Wullstein C, Koppen M, Gross E: Laparoscopic treatment of colonic perforations related to colonoscopy. Surg Endosc 1999;13:484-487.

3 Maunder RJ, Pierson DJ, Hudson LD: Subcutaneous and mediastinal emphysema, pathophysiology diagnosis and management. Arch Intern Med 1984;144:1447-1453. 
Tiwari et al.: Recognition of Extraperitoneal Colonic Perforation following Colonoscopy: A Review of the Literature

4 Fatima H, Rex DK: Minimizing endoscopic complications: colonoscopic polypectomy. Gastrointest Endosc Clin N Am 2007;17:145-156, viii.

5 Waye JD, Kahn 0, Auerbach ME: Complications of colonoscopy and flexible sigmoidoscopy. Gastrointest Endosc Clin N Am 1996;6:343-377.

6 Panteris V, Haringsma J, Kuipers EJ: Colonoscopy perforation rate, mechanisms and outcome: from diagnostic to therapeutic colonoscopy. Endoscopy 2009;41:941-951.

7 Damore LJ, Rantis PC, Vernava AM, et al: Colonoscopic perforations. Etiology, diagnosis, and management. Dis Colon Rectum 1996;39:1308-1314.

8 Anderson ML, Pasha TM, Leighton JA: Endoscopic perforation of the colon: lessons from a 10-year study. Am J Gastroenterol 2000;95:3418-3422.

-9 Weber DJ, Rodney WM, Warren J: Management of suspected perforation following colonoscopy: a case report. Fam Pract 1993;36:567-571.

10 Waye JD, Kahn 0, Auerbach ME: Complications of colonoscopy and flexible sigmoidoscopy. Gastrointest Endosc Clin N Am 1996;6:343-377.

11 Hall C, Dorricott NJ, Donovan IA, Neoptolemos JP: Colon perforation during colonoscopy: operative versus non-operative management. Br J Surg 1991;78:542-544.

12 Hansen AJ, Tessier DJ, Ander son ML, et al: Laparoscopic repair of colonoscopic perforations: indications and guidelines. J Gastrointest Surg 2007;11:655-659.

13 Iqbal CW, Chun YS, Farley DR: Colonoscopic perforations: a retrospective review. J Gastrointest Surg 2005;9:1229-1235.

14 Teoh AY, Poon CM, Lee JF, et al: Outcomes and predictors of mortality and stoma formation in operative management of colonoscopic perforations: a multicenter review. Arch Surg 2009;144:9-13.
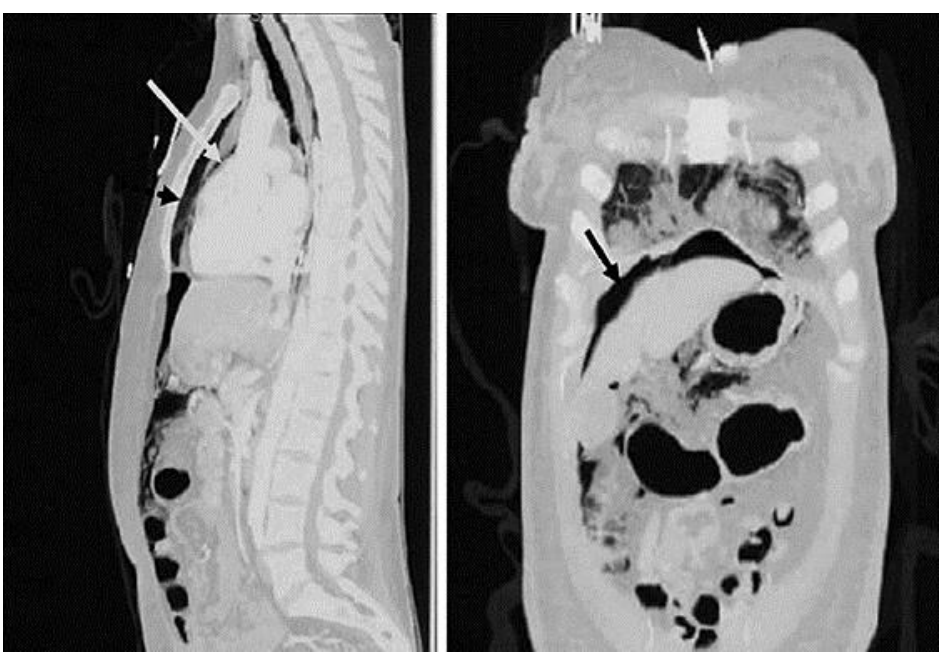

Fig. 1. Computerized tomography of the chest and abdomen showing pneumomediastinum (broken arrow), pneumopericardium (white arrow), and pneumoperitoneum (black arrow). 


\section{Case Reports in \\ Gastroenterology}

Case Rep Gastroenterol 2017;11:256-264
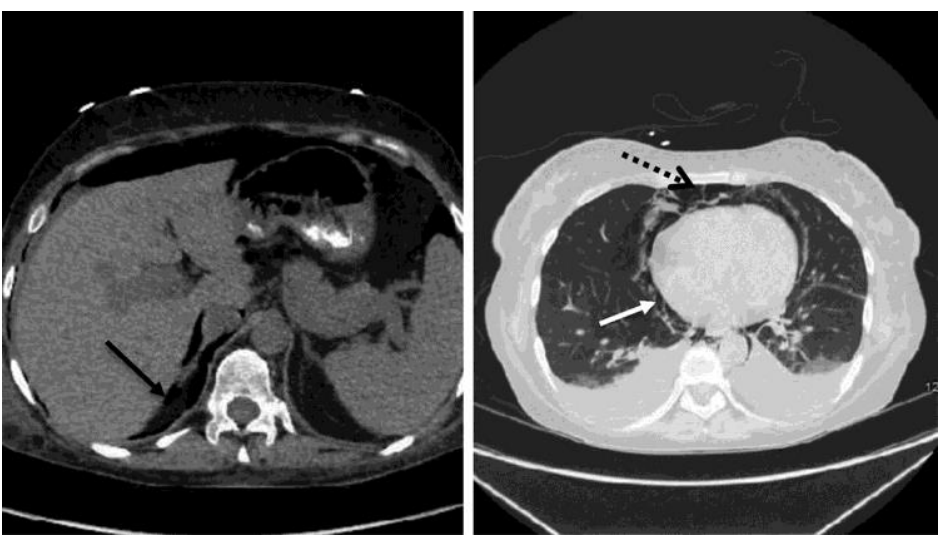

Fig. 2. Computerized tomography of the abdomen (left) and chest showing pneumoperitoneum (black arrow), pneumomediastinum (broken arrow), and pneumopericardium (white arrow).

Tiwari et al.: Recognition of Extraperitoneal Colonic Perforation following Colonoscopy: A Review of the Literature

(c) 2017 The Author(s). Published by S. Karger AG, Basel www.karger.com/crg 
Tiwari et al.: Recognition of Extraperitoneal Colonic Perforation following Colonoscopy: A

Review of the Literature

Table 1. Reported cases of extraperitoneal and combined colonic perforation after diagnostic and therapeutic colonoscopy

$\begin{array}{lll}\text { Pts First author, year } \quad \text { Procedure type } & \begin{array}{l}\text { Time of } \\ \text { onset of } \\ \text { symptoms }\end{array} & \text { Clinical features }\end{array}$

$\begin{array}{llll}\text { Imaging findings } & \begin{array}{l}\text { Site of } \\ \text { perforation }\end{array} & \text { Management } \\ \mathrm{PP}^{*} \quad \mathrm{PT}^{*} \quad \mathrm{PM}^{*} & \end{array}$

PP* $\mathrm{PT}^{*} \quad \mathrm{PM}^{*}$

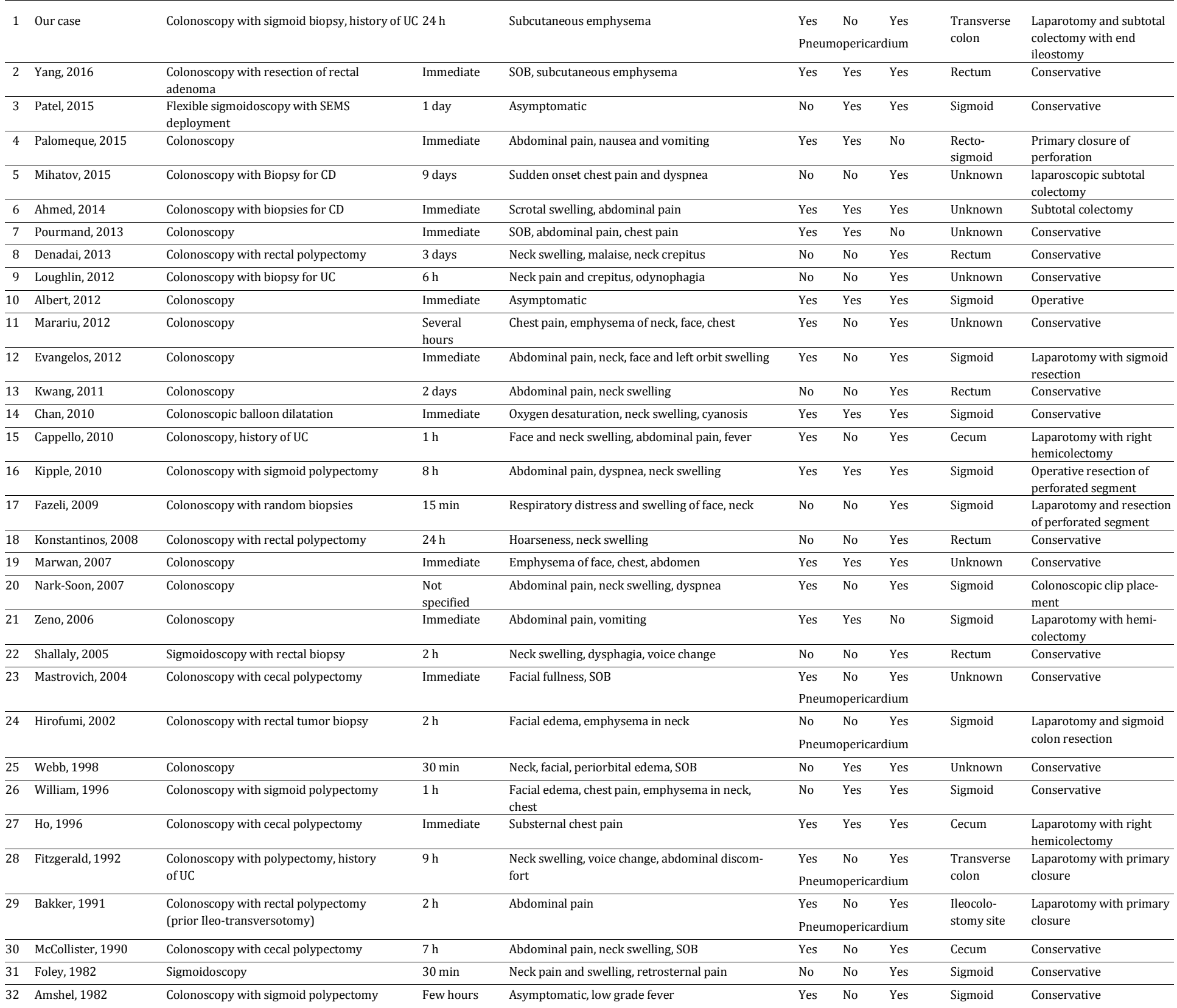

PP, pneumoperitoneum; PT, pneumothorax; PM, pneumomediastinum; UC, ulcerative colitis; CD, Crohn disease; SEMS, self-expanding metallic stent; SOB, shortness of breath. 
Table 2. Summary of findings in isolated extraperitoneal and combined intra- and extraperitoneal perforations ( $n=32$ cases)

\begin{tabular}{lcc}
\hline & $\begin{array}{l}\text { Extraperitoneal } \\
(n=12), n(\%)\end{array}$ & $\begin{array}{l}\text { Combined } \\
(n=20), n(\%)\end{array}$ \\
\hline Type of procedure & & \\
$\quad$ Diagnostic only & $3(25)$ & $9(45)$ \\
Diagnostic with biopsy & $5(42)$ & $2(10)$ \\
Therapeutic (including polypectomy) & $4(33)$ & $9(45)$ \\
Onset of symptoms & & \\
Immediate & $4(33)$ & $12(60)$ \\
$>1$ h and <24 h & $3(25)$ & $6(30)$ \\
$\geq 24$ h & $5(42)$ & $1(10)^{\mathrm{a}}$ \\
Clinical features & & \\
Neck swelling & $10(83)$ & $11(55)$ \\
Dyspnea & $3(25)$ & $5(25)$ \\
Chest pain & $3(25)$ & $3(15)$ \\
Abdominal pain & $1(8)$ & $10(50)$ \\
Asymptomatic & $1(8)$ & $2(10)$ \\
Imaging & & \\
Pneumoperitoneum & $0(0)$ & $20(100)$ \\
Pneumothorax & $3(25)$ & $10(50)$ \\
Pneumomediastinum & $12(100)$ & $17(85)$ \\
Pneumopericardium & $1(8)$ & $4(20)$ \\
Site of perforation & & $9(45)$ \\
Rectosigmoid & $9(75)$ & $3(15)$ \\
Cecum & $0(0)$ & $3(15)$ \\
Other & $0(0)$ & $5(25)$ \\
Unknown & $3(25)$ & $8(40)$ \\
Management & $9(75)$ & \\
Conservative & $3(25)$ & $(60)$ \\
Surgical & & \\
\hline
\end{tabular}

a One case with unknown duration of onset of symptoms excluded. 